\title{
A Research Article on Nanogel as Topical Promising Drug Delivery for Diclofenac sodium
}

\author{
Swati Talele ${ }^{1 *}$, Preetam Nikam¹, Braja Ghosh1, Chaitali Deore ${ }^{2}$, Ashwini Jaybhave ${ }^{2}$, Anil Jadhav ${ }^{2}$ \\ ${ }^{1}$ Department of Pharmaceutics, Sandip Institute of Pharmaceutical Sciences, Nashik, INDIA. \\ ${ }^{2}$ Department of Quality Assurance, Sandip Institute of Pharmaceutical Sciences, Nashik, INDIA.
}

\begin{abstract}
Background: Transdermal delivery of drug is promising but challenging system is available for local as well as systemic effect of drug. The prolonged residence of drug formulation in the skin is important for transdermal drug delivery. Objective: The objective of the present investigation was to develop a nanogel with reduced particle size in order to improve the bioavailability of the anti-inflammatory drug, Diclofenac sodium. Methods: The present study is to formulate nanosizes dispersion of diclofenac sodium by emulsionsolvent diffusion method and incorporation of gelling agent to produce nanogel. The formulation are characterized for particle size ranging from 100-400 nm. A drug named diclofenac sodium used in rheumatoid disorders and chronic inflammatory diseases. Results: Glycerol: Water (20:80) co-solvent system is selected for preparing diclofenac sodium nanogels using different polymers and has better permeability coefficient than alcohol: water co-solvent. Permeation through cellophane membrane was carried using $0.9 \% \mathrm{w} / \mathrm{v}$ sodium chloride using receptor fluid in franz diffusion cell $\left(1.74 \mathrm{~cm}_{2}\right)$. Gels containing diclofenac sodium with eudragit polymer shown better permeability coefficient. Conclusion: Diclofenac sodium nanogels formulated using carbopol with permeation enhancer has shown better flux enhancement in comparison with nanogels formulated using HPMC and methyl cellulose. It has been concluded that diclofenac sodium nanogels using carbopol 940 as gelling agent and Eudragit S-100 has shown better flux enhancement with propylene glycol as permeation enhancer.
\end{abstract}

Key words: Diclofenac sodium, TDDS, Eudragit S-100, Glycerol, Carbopol-940, Cellophane membrane.

\section{INTRODUCTION}

Transdermal delivery of drug is promising but challenging system is available for local as well as systemic effect of drug. The entry of drug through the stratum corneum may follow the intercellular, transcellular or appendageal route. The intercellular route is the more common pathway of the drug permeation through the skin. Nanogel can be termed as dispersion of hydrogel by physical and chemical cross-linking polymer at nanoscale size. Nanogel exhibit properties between those of solids and liquids. It consist of small amount of solid components entangled with polymers dispersed in large volume of liquid in which solids form 3D network forming the nanoscale size leading to high surface area providing biconjugation of active targeting sites. Nanogels combine the advantage of hydrogels inherting the property of nanoscale size. Nanogel network provide high specific form can host and protect drug molecules. The release of the drug molecules can be incorporated by providing high-affinity functional groups. Nanogels are able to carry encapsulated drug molecules to targeted tissues or cell structures without premature leakage of the drug into the blood stream or other tissues. Nanogel has been the form having size ranging from 1-100 $\mathrm{nm}$. In oral drug delivery, nanogels have been used to protect unstable peptides from harsh manufacturing and physiological environments and to enhance the drug absorption at specific
Submission Date: 23-03-2017; Revision Date: 18-05-2017; Accepted Date: 25-07-2017

DOI: 10.5530/ijper.51.4s.86 Correspondence: Swati Talele*, Assistant Professor, Department of Pharmaceutics, Sandip Institute of Pharmaceutical Sciences, Nashik,-422213, INDIA. Phone: 9850165808 E-mail: swatitalele77@gmail. com

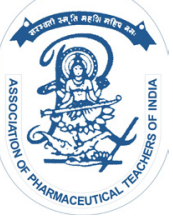

www.ijper.org 
sites. The nanogel of Diclofenac sodium has been used as Non-Steroidal anti-inflammatory drug (NSAID's) for its anti-inflammatory and analgesic effect. Oral route causes irritation and ulceration of GIT. An improved Diclofenac formula with high degree of skin permeation can be useful in treatment of not only inflamed tissues but also inflammatory pain.

The present study was conducted to design and evaluate Diclofenac sodium nanogel which provides prolonged release, increase the residence time of drug on the skin thereby enhance bioavailability.

\section{MATERIALS AND METHOD}

Diclofenac sodium and Eudragit S-100 was purchased from Evonik industries, Mumbai. Carbopol 940 and Glycerol was gift sample from Loba Chemie Pvt. Ltd., Mumbai. Tween 80 was purchased from S.D. Fine chemical Ltd., Mumbai. Triethanolamine was purchased from Spectrochem, Mumbai.

\section{METHOD}

\section{Preparation of Diclofenac Sodium Nanogel}

Accurately weighed quantity of Drug, Eudragit S-100 (polymer), and Tween- 80 as stabilizer are dissolved in glycerol while stirring. Prepared aqueous phase containing Carbopol-940 dissolved in water with continuous stirring and heat. These drug containing phase is sonicated on Ultra sonic bath sonicator. The drug phase is added drop by drop into the aqueous phase during homogenization to form emulsion. The emulsion converted into nanodroplets by homogenizer which formed $\mathrm{O} / \mathrm{W}$ emulsion. Homogenization was continued for one hour. Triethanolamine added to form the gel with continuous stirring to nanogel. Batch A1, A2, A3 was prepared at highest rpm 8000 with variation in composition. Whereas prototype batches B1, B2, B3 and C1, C2, C3 prepared at different rpm 5000, 6000, 7000 using homogenizer respectively. As shown in Table 1, Table 2, Table 3.

\section{Evaluation Parameters}

Appearance: The prepared gel bases were inspected visually for clarity, colour and presence of any particles.

\section{Homogeneity}

All developed gels were tested for homogeneity by visual inspection after the gels have been set in the container. They were tested for their appearance and presence of any aggregates.

\section{Measurement of particle size of formulation}

The mean size of the selected nanogels were determined by using Malvern Mastersizer 2000 MS. The mean particle size was recorded.

\section{PH measurement}

The $\mathrm{pH}$ measurement was carried out by using calibrated digital type $\mathrm{pH}$ meter by dipping the glass electrode and the reference electrode completely into gel system so as to cover the electrodes.

\section{Drug content}

For the estimation of the drug in gel, Diclofenac sodium was extracted from $1 \mathrm{gm}$ of gel formulation with $50 \mathrm{ml}$ of phosphate buffer 6.8 and mixture was filtered through membrane filter (pore size $0.45 \mu \mathrm{m}$ ). From this, $2 \mathrm{ml}$ was pipette out and made upto $10 \mathrm{ml}$. The absorbance of the sample was determined spectrophotometrically at $276 \mathrm{~nm}$. The concentration of Diclofenac sodium was estimated from the calibration curve.

\section{In vitro Release studies}

The drug release from the formulation was determined by using the apparatus known as Franz Diffusion Cell, which consist of a cylindrical glass tube which was opened at both the ends. $1 \mathrm{gm}$ of gel equivalent to $10 \mathrm{mg}$ of Diclofenac sodium was spread uniformly on the surface of cellophane membrane (previously soaked in medium for $24 \mathrm{hrs}$ ) and was fixed to the one end of tube. The whole assembly was fixed in such a way that the lower end of tube containing gel was just touches (1-2 mm deep) the surface of diffusion medium i.e. $100 \mathrm{ml}$ of pH 6.8 phosphate buffer contained in $100 \mathrm{ml}$ beaker. The assembly was placed on thermostatic hot plate with magnetic stirrer and maintained at temperature $37^{\circ} \pm 2^{\circ}$ the contents were stirred using magnetic bar at $100 \mathrm{rpm}$ for a period of $24 \mathrm{hrs}, 5 \mathrm{ml}$ of samples were withdrawn at different time intervals. This $5 \mathrm{ml}$ was diluted upto 10 $\mathrm{ml}$ of fresh phosphate buffer ( $\mathrm{pH}$ 6.8) and sample were analyze at $276 \mathrm{~nm}$ in UV-Vis spectrometer for diclofenac sodium.

Skin irritation test: Test for irritation was performed on human volunteers. For each gel, four volunteers were selected and $1.0 \mathrm{~g}$ of formulated gel was applied on an area of 2 square inch to the back of hand. The volunteers were observed for lesions or irritation.

\section{Spreadability}

Spreadibility is determined by apparatus suggested by Mutimer. It consist of wooden block, which is provided 
by a pulley at one end. By this method, spreadibility is measured on the basis of "Slip" and "Drag". A ground glass slide is fixed on this block. A sample of $0.1 \mathrm{~g}$ of nanogel under study is placed on this ground slide. The gel is fixed on the beach formula was pressed between two slides and a $1 \mathrm{~kg}$ weight is placed on the top of two slides and left for about $5 \mathrm{~min}$ to expel air and to provide a uniform film of the nanogel between two slides. Excess of the gel is scrapped from edges. The top plate is then subjected to pull the weight. With help of string attaches to the hook and the time required by top slide to cover the distance is noted. A shorter interval indicate better spreadibility, spreadability was calculated by using the formula,

$\mathrm{S}=\mathrm{M} \cdot \mathrm{L} / \mathrm{T}$,

Where, $\mathrm{S}=$ spreadability, L=Length of glass slide, $\mathrm{M}=$ weight tied to upper slide,

$\mathrm{T}=$ Time taken to separate the slides.

\section{Extrudability:}

It is a usual empirical test to measure the force required to extrude the material from tube. The method applied for determination of applied shear in the region of the rheogram corresponding to a shear rate exceeding the yield value and exhibiting plug flow. The method adopted for evaluating nanogel formulation for extrudability is based upon the quantity in percentage of nanogel and nanogel extruded from lacquered aluminium collapsible tube on application of weight in grams required at least $0.5 \mathrm{~cm}$ ribbon of nanogel in $10 \mathrm{sec}$. The measurement of extrudability of each formulation shows the triplicate and averages value is presented.

Extrudability $=$ Applied weight to extrude the nanogel from tube (in gm)/ Area (in cm2).

Rheological Studies: Brookfield viscometer was used for the studies. First, the spindle was dipped into the gel till the notch on the spindle touched the gel surface. $3 \mathrm{gm}$ each of gel I and gel II (Stability chamber and Room temperature) was used in the study. The spindle no.61, 63, 64 was selected based on viscosity of gel. The dial readings were taken at 50,100,150,250rpm and viscosity was measured. ${ }^{2,4,5,6,7}$

From the evaluation parameter performed for the three prototype batches, the result for the batch A-1 was found to be satisfactory in all attributes and hence selected for trial batches. As shown in Table 7, Table 8, Table 9.

The evaluation parameter was performed on marketed product as shown in Table 11.

\section{RESULTS AND DISSCUSIONS}

\section{FTIR Spectroscopy ${ }^{7}$}

The FTIR spectrum for is shown in Figure 1 and in Diclofenac sodium interpretation of FTIR spectra is given in Table 4.

FTIR spectrum of drug sample showed all the peaks corresponding to the functional groups present in the structure of Diclofenac sodium. From FTIR spectrum it was concluded that the drug sample was in pure form.

\section{Differential Scanning Calorimetry Studies ${ }^{8}$}

Pure drug- Diclofenac sodium

Polymer- Eudragit S-100 Binary Mixture- Drug + Polymer DSC thermogram of Diclofenac sodium is shown in the Figure 2. DSC studies indicate a sharp endothermic peak at $282^{\circ} \mathrm{C}$ corresponding to the melting point of the sample which matches with the melting point of Diclofenac sodium indicating the purity of drug.

From the DSC overlay thermogram of pure drug and physical mixture with Eudragit S-100; it can be concluded that the excipients and drug doesn't have any interaction with each other. Also the drug did not form a complex with the excipients as the endothermic peaks remained unchanged in position.

\section{UV Spectroscopy ${ }^{8,9}$}

After studying the UV spectra of diclofenac sodium, it was found that drug shows absorbances at 226 and $276 \mathrm{~nm}$ but maximum absorbance was at $276 \mathrm{~nm}$ when solution is prepared in distilled water. So, $276 \mathrm{~nm}$ was considered as $\lambda_{\max }$. UV spectra diclofenac sodium is shown in Figure 3.

\section{Effect of change in $\mathrm{pH}$ on $\lambda_{\max }{ }^{9}$}

$\lambda_{\max }$ of drug was observed by making its solution in different $\mathrm{pH}$ to check the effect of $\mathrm{pH}$ on $\lambda_{\max }$. Result of the same is given in Table 5.

There was no significant change in $\lambda_{\max }$ of Diclofenac sodium at different $\mathrm{pH}$. So calibration plot can be constructed by using distilled water and can be used for quantitative evaluation purpose; though the medium of evaluation of release is phosphate buffer $\mathrm{pH}$ 7.4.

\section{Calibration curve of Diclofenac sodium ${ }^{10}$}

The calibration curve for diclofenac sodium in phosphate buffer 6.8 is shown in Figure 4 and its observation values in Table 6. The graph of absorbance vs. concentration was found to be linear in the concentration range of $4-24 \mu \mathrm{g} / \mathrm{ml}$ at $276 \mathrm{~nm}$. The $\mathrm{R}^{2}$ of the calibration curve was found to be 0.999 . 
Trial batches

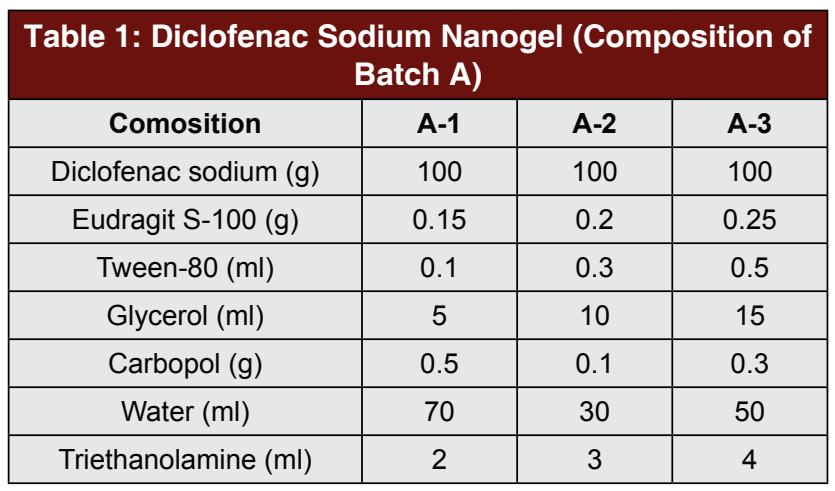

\begin{tabular}{|c|c|c|c|}
\hline $\begin{array}{c}\text { Table 2: Diclofenac Sodium Nanogel (Composition of } \\
\text { Batch B) }\end{array}$ \\
\hline Composition & B-1 & B-2 & B-3 \\
\hline Diclofenac sodium $(\mathrm{g})$ & 100 & 100 & 100 \\
\hline Eudragit S-100 $(\mathrm{g})$ & 0.15 & 0.15 & 0.15 \\
\hline Tween-80 (ml) & 0.1 & 0.1 & 0.1 \\
\hline Glycerol $(\mathrm{ml})$ & 5 & 5 & 5 \\
\hline Carbopol $(\mathrm{g})$ & 0.1 & 0.1 & 0.1 \\
\hline Water $(\mathrm{ml})$ & 30 & 30 & 30 \\
\hline Triethanolamine $(\mathrm{ml})$ & 2 & 2 & 2 \\
\hline
\end{tabular}

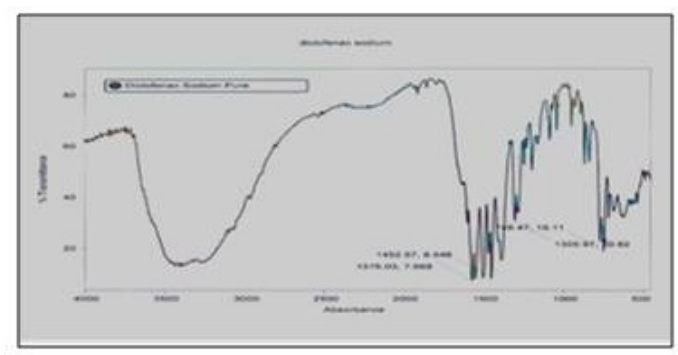

Figure 1: FTR spectrum of pure Diclofenac sodium

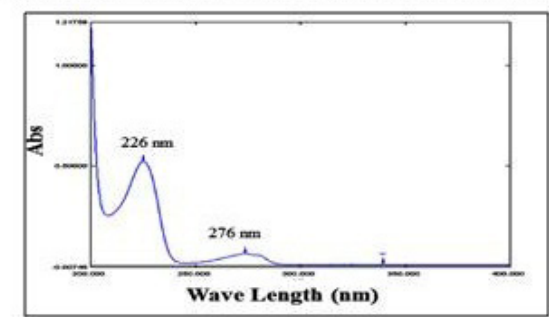

Figure 3 : UV spectra of Diclofenac sodium

\begin{tabular}{|c|c|c|c|}
$\begin{array}{c}\text { Table 3: Diclofenac Sodium Nanogel (Composition of } \\
\text { Batch C) }\end{array}$ \\
\hline Composition & C-1 & C-2 & C-3 \\
\hline Diclofenac sodium $(\mathrm{g})$ & 100 & 100 & 100 \\
\hline Eudragit S-100 (g) & 0.15 & 0.15 & 0.15 \\
\hline Tween-80 (ml) & 0.1 & 0.1 & 0.1 \\
\hline Glycerol (ml) & 5 & 5 & 5 \\
\hline Carbopol (g) & 0.1 & 0.1 & 0.1 \\
\hline Water $(\mathrm{ml})$ & 30 & 30 & 30 \\
\hline Triethanolamine (ml) & 2 & 2 & 2 \\
\hline
\end{tabular}

\begin{tabular}{c|c|}
$\begin{array}{c}\text { Table 4: Interpretation of FTIR spectrum of pure } \\
\text { Diclofenac sodium. }\end{array}$ \\
\hline Peaks $\mathbf{c m}^{-1}$ & Groups \\
\hline 3351 & O-H \\
\hline 1208 & C-O \\
\hline 2936 & Aliphatic C-H \\
\hline 1179 & Asymmetric C-O-C \\
1042 & Symmetric C-O-C \\
\hline
\end{tabular}

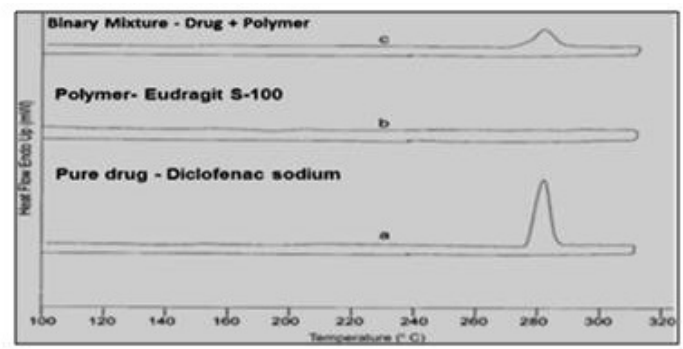

Figure 2: DSC themogram of didofenac sodium+polymer+binary mixture

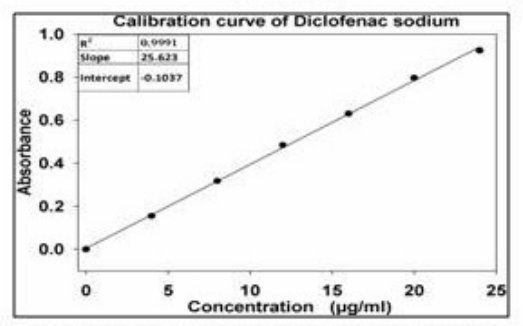

Figure 4: Calibration curve of Didofenac sodium

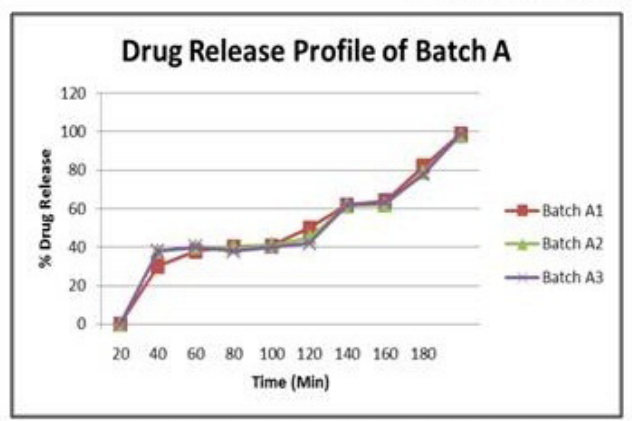

Fig.5 Drug Release profile of Batch A 


\begin{tabular}{|c|c|}
\hline \multicolumn{2}{|c|}{ Table 5: Effect of $\mathbf{p H}$ on $\lambda_{\max }$} \\
\hline Drug solution in $\mathbf{p H}$ & $\boldsymbol{\lambda}_{\max }$ \\
\hline 6.8 & $276 \mathrm{~nm}$ \\
\hline 7.4 & $276 \mathrm{~nm}$ \\
\hline
\end{tabular}

Trial batches evaluation

\begin{tabular}{|c|c|c|}
\hline \multicolumn{3}{|c|}{ Table 6: Calibration curve values of Diclofenac sodium. } \\
\hline Sr. No. & Concentration $(\mu \mathbf{g} / \mathbf{m l})$ & Absorbance \\
\hline 1 & 0 & 0 \\
\hline 2 & 4 & 0.1548 \\
\hline 3 & 8 & 0.3173 \\
\hline 4 & 12 & 0.4842 \\
\hline 5 & 16 & 0.6303 \\
\hline 6 & 20 & 0.7963 \\
\hline 7 & 24 & 0.9237 \\
\hline$R^{2}$ & 1 & \\
\hline Slope & 25.61 & \\
\hline Intercept & -0.1020 & \\
\hline
\end{tabular}

\begin{tabular}{|c|c|c|c|}
\hline \multicolumn{5}{|c|}{ Table 7: Evaluation Parameters for Batch A } \\
\hline Evaluation parameters & A-1 & A-2 & A-3 \\
\hline Appearance & Clear & Clear & Clear \\
\hline Homogenicity & Homogeneous & Homogenous & Homogenous \\
\hline Particle size $(\mathrm{nm})$ & 165 & 189 & 213 \\
\hline $\mathrm{pH}$ & $6.9 \pm 0.00$ & $6.5 \pm 0.02$ & $6.2 \pm 0.20$ \\
\hline Drug content \pm SD & $98.8 \pm 0.02$ & $96.5 \pm 0.02$ & $97.8 \pm 0.04$ \\
\hline In vitro drug release $(\%)$ & $96.72 \pm 0.0784$ & $94.75 \pm 0.963$ & $92.78 \pm 0.77$ \\
\hline Skin irritation test & No irritation & No irritation & No irritation \\
\hline Spreadability $(\mathrm{g} . \mathrm{cm} / \mathrm{s})$ & $6.3 \pm 0.5$ & $6.7 \pm 0.6$ & $6.0 \pm 0.6$ \\
\hline Extrudability $(\mathrm{g})$ & $279 \pm 0.7$ & $268 \pm 0.5$ & $254 \pm 0.7$ \\
\hline Viscosity in cp at $50(\mathrm{rpm})$ & 9563 & 8562 & 8000 \\
\hline
\end{tabular}

\begin{tabular}{|c|c|c|c|}
\hline \multicolumn{5}{|c|}{ Table 8: Evaluation Parameters for Batch B } \\
\hline Evaluation parameters & B-1 & B-2 & B-3 \\
\hline Appearance & Clear & Clear & Clear \\
\hline Homogenicity & Homogenous & Homogenous & Homogenous \\
\hline Particle size $(\mathrm{nm})$ & 165 & 175 & 220 \\
\hline $\mathrm{pH}$ & $6.8 \pm 0.00$ & $6.7 \pm 0.02$ & $6.5 \pm 0.20$ \\
\hline Drug content \pm SD & $98.8 \pm 0.02$ & $98.5 \pm 0.02$ & $98.8 \pm 0.04$ \\
\hline In vitro drug release $(\%)$ & $96.72 \pm 0.0784$ & $95.75 \pm 0.963$ & $95.78 \pm 0.77$ \\
\hline Skin irritation test & No irritation & No irritation & No irritation \\
\hline Spreadability $(\mathrm{g} . \mathrm{cm} / \mathrm{s})$ & $6.6 \pm 0.5$ & $6.5 \pm 0.6$ & $6.7 \pm 0.6$ \\
\hline Extrudability $(\mathrm{g})$ & $279 \pm 0.7$ & $270 \pm 0.5$ & $260 \pm 0.7$ \\
\hline Viscosity in cp at $50(\mathrm{rpm})$ & 9863 & 9582 & 9888 \\
\hline
\end{tabular}

\begin{tabular}{|c|c|c|c|}
\hline \multicolumn{5}{|c|}{ Table 9: Evaluation Parameters for Batch C } \\
\hline Evaluation parameters & C-1 & C-2 & C-3 \\
\hline Appearance & Clear & Less clear & Clear \\
\hline Homogenicity & Homogeneous & Homogeneous & Homogeneous \\
\hline Particle size $(\mathrm{nm})$ & 165 & 160 & 160 \\
\hline $\mathrm{pH}$ & $6.5 \pm 2$ & $6.7 \pm 1$ & $6.2 \pm 2$ \\
\hline Drug content \pm SD & $98.2 \pm 0.029$ & $98.6 \pm 0.04$ & $98.5 \pm 0.072$ \\
\hline In vitro drug release $(\%)$ & $93.25 \pm 0.903$ & $95.72 \pm 0.861$ & $94.3 \pm 0.85$ \\
\hline Spreadability (g.cm/s) & 6.3 & 6.4 & 6.3 \\
\hline Extrudability $(\mathrm{g})$ & 254 & 243 & 254 \\
\hline Viscosity in cp at $50(\mathrm{rpm})$ & 9585 & 9588 & 8500 \\
\hline
\end{tabular}


Table 10: Stability data of Optimized Formulation

\begin{tabular}{|c|c|c|}
\hline Time period & $\begin{array}{c}\text { Particle } \\
\text { size(nm) }\end{array}$ & Total drug content(\%) \\
\hline Initial & 165 & $98.2 \pm 0.029$ \\
\hline \multicolumn{3}{|c|}{ After storage $\left(40^{\circ} \mathrm{C} \pm 2^{\circ} \mathrm{C}\right.$ and $\left.75 \% \pm 5 \% \mathrm{RH}\right)$} \\
\hline 1 Month & 162 & $95.72 \pm 0.861$ \\
\hline 2 Month & 160 & $94.3 \pm 0.85$ \\
\hline 3Month & 164 & $93.25 \pm 0.903$ \\
\hline
\end{tabular}

Table 11: Evaluation Parameter of marketed product

\begin{tabular}{|c|c|}
\hline Evaluation Parameters & Market product (Serrini) \\
\hline Appearance & Clear \\
\hline Homogenicity & Homogenous \\
\hline Particle size $(\mathrm{nm})$ & 168 \\
\hline $\mathrm{pH}$ & $6.5 \pm 0.2$ \\
\hline Drug content \pm SD & $96.8 \pm 0.02$ \\
\hline In vitro drug release $(\%)$ & $95.72 \pm 0.0784$ \\
\hline Skin irritation test & No irritation \\
\hline Spreadability $(\mathrm{g} . \mathrm{cm} / \mathrm{s})$ & $6.6 \pm 0.5$ \\
\hline Extrudability $(\mathrm{g})$ & $275 \pm 0.7$ \\
\hline Viscosity in $\mathrm{cp}$ at $50(\mathrm{rpm})$ & 9400 \\
\hline
\end{tabular}

\section{Stability batches evaluation}

The stability studies were carried out on optimized formulation. The samples were stored at $40^{\circ} \mathrm{C} \pm 2{ }^{\mathrm{O}} \mathrm{C}$ and $75 \% \pm 5 \%$ relative humidity for three months as per $\mathrm{ICH}$ guidelines. After 1, 2 and 3 months samples were withdrawn and tested for appearance, $\mathrm{pH}$, particle size, drug content, spreadability, extrudability, viscosity.

\section{Stability data of Optimized Formulation}

The evaluation parameter performed for the trial batches $(\mathrm{B}$ and $\mathrm{C})$ are the same as done for the above prototype batch (A) and they are appearance, homogeneity, particle size measurement, $\mathrm{pH}$ measurement, drug entrapment efficiency, drug content, in vitro drug release, skin irritation study, spreadibility, extrudability, rheological study, stability batches From the evaluation parameter result of trial batches we found Batch-A1 as the optimized batch and further experimental design is formulated. Figure 5.

The evaluation parameter performed for the trial batches (B and C) are the same as done for the above prototype batch (A) and they are appearance, homogeneity, particle size measurement, $\mathrm{pH}$ measurement, drug entrapment efficiency, drug content, in vitro drug release, skin irritation study, spreadibility, extrudability, rheological study, stability batches From the evaluation parameter result of trial batches we found Batch-A1 as the optimized batch and further experimental design is formulated. As shown in Table 10.

\section{CONCLUSION}

Nanogel formulation containing Diclofenac sodium was successfully prepared and shows effective as well as better carrier for the transdermal/topical preparation. The formulated nanogel was optimized for homogenicity, particle size, $\mathrm{pH}$, drug content, in vitro drug release, skin irritation test, spreadability, extrudability, and viscosity. Administration of this through dermal route bypass the disadvantages of oral route and maintain the consistently plasma levels for the therapy for single dose. The initial release rate from each formulation was very rapid, this may be due to incomplete gel formation in the earlier time period, but the release became slow in latter period after complete gel formation. The release profiles exhibited an inflection point, which indicated gel formation on the diffusion membrane in donor compartment of diffusion cell. During gel formation, formulation got converted into the gel phase and thus drug release became slow. The results showed that the formed gels had the ability to retain diclofenac sodium for the duration. The production of the formulation is also proved to be better and cost effective in comparison with oral dosage forms.

\section{ACKNOWLEDGEMENT}

The authors are thankful to the management, principal and the staff of Sandip Institute of Pharmaceutical Sciences for their kind help and support.

\section{CONFLICT OF INTEREST}

There are no conflict of interest.

\section{ABBREVIATION USED}

nm: Nanometer; GIT: Gastrointestinal tract; gm: Gram; ml: Milliliter; kg: Kilogram; cm: Centimeter; rpm: Revolutions per minute; ICH: International Conference on Harmonisation; $\mu \mathrm{m}$ : Micrometer; $\mathbf{m m}$ : Milimeter; sec.: Second; $\mu \mathrm{g} / \mathrm{ml}$ : Microgram per mililiter; g.cm/s: Gram centimeter per second; RH: Relative Humidity.

\section{REFERENCES}

1. Nahas E, Fakhry G, Shereen et al. Effect of various penetration enhancers on diclofenac sodium. Asian J Pharm. 2011;5:33.

2. Kumar JA, Pullakanda N, Prabu SL, et al. Transdermal Drug Delivery System: An Overview, International J. of Pharm. Sciences Review and Research. 2010;3(2):49. 
3. Barry BW. Novel mechanisms and devices to enable successful transdermal drug delivery. European Journal of Pharma Science. 2001;14(2):101-14.

4. Dinda SC. Advances in Pharmaceutical Techonology. School of Pharmaceutical Education and Research. 2011;69-82.

5. PhatakA, Jorwekar P, Chaudhari P. Nanosuspension a promising nanocarrier as a drug delivery system. Research $\mathrm{J}$ Pharm Dosage Forms and Tech. 2011;3:176.

6. The Merck Index, $13^{\text {th }}$ edition. 2001;6909.

7. Williams AC, Barry BW. "Penetration Enhancers". Advanced Drug Delivery Reviews, 2004;56;603-18.

8. William B, Liechty NA, et al. Expert opinion: Responsive polymers nanoparticles in cancer therapy. European Journal of Pharmaceutics. 2012;80(2):241-6.

9. Walters KA. "Penetration Enhancers and Their Use in Transdermal Therapeutic Systems," in Transdermal Drug Delivery-Development Issues and Research Initiatives. Hadgraft J and Guy R H. 1989;197-246.

10. Zeng-Ying Q, Rui Z, Fu-Sheng D, et al. Multi-responsive nanogels containing motifs of ortho ester, oligo and disulfide linkage as carriers of hydrophobic anti-cancer drugs. Journal of Controlled Release. 2011;57-68.

11. Gupta SK, Bansal P, Bhardwaj RK. Comparison of analgesic and antiinflammatory activity of meloxicam gel with Diclofenac sodium and piroxicam gel in animal models. Skin Pharmacol Applied Skin Physiol. 2002;15:105-11.

\section{PICTORIAL ABSTRACT}

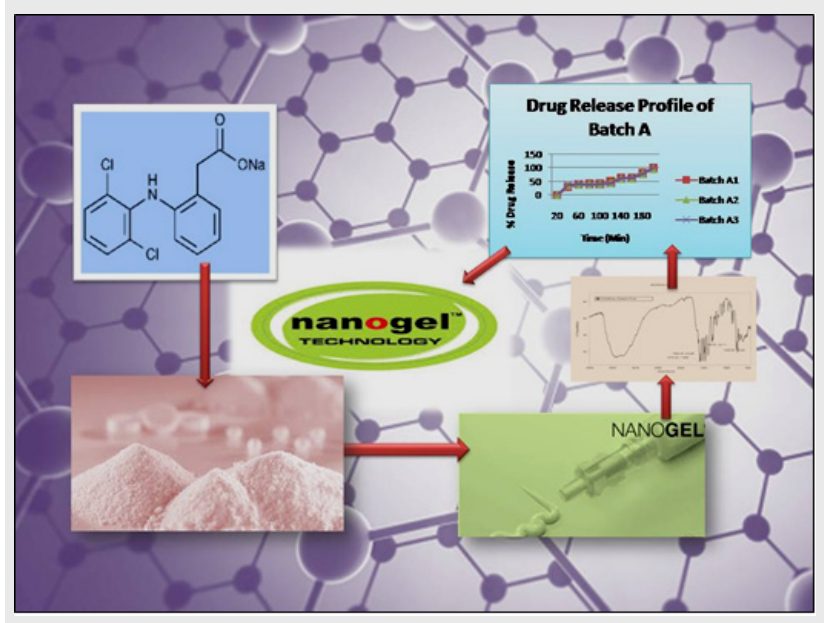

\section{About Authors}

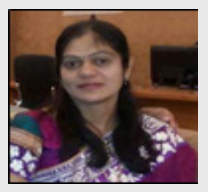

Swati Talele: She is working as an Assistant Professor, in the Department of Pharmaceutics at Sandip Institute of Pharmaceutical Sciences, Nashik. Currently she is pursuing her $\mathrm{Ph} \mathrm{D}$. programme at Savitribai Phule Pune University, Pune, Maharashtra. Mrs. Swati has research experience in the area of Pharmaceutical analysis, Phytochemical analysis, Formulation of Nanoparticle for Drug delivery applications.

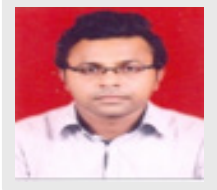
Phule Pune University, Pune, Maharashtra.
12. Guy RH. Transdermal drug delivery, In Drug Delivery Handbook of Experimental Pharmacology. Springer-Verlasa. 2010;399-410.

13. Idson B, Lazarus J. "Semisolids," in The Theory and Practice of Industrial Pharmacy, L. Lachman, H.A. Lieberman, and J. L. Kanig, Eds, 1991;534-63.

14. Kabanov AV, Vinogradov SV. Nanogels as pharmaceutical carriers:finite networks of infinite capabilities. Angew Chem Int Ed. 2009;48:541-2.

15. Lionberger DR, Brennan MJ. Dermal NSAIDs for the treatment of pain due to soft tissue injury; Diclofenac epolamine dermal patch. Journal Pain Les. 2010;3:223-33.

16. William B, Liechty NA. Expert opinion: Responsive polymers nanoparticles in cancer therapy. European Journal of Pharmaceutics. 2012;80:241-6.

17. Nair B, Gjeure-Taylor R. A review of Topical Diclofenac use in Musculoskeletal Disease. Pharmaceuticals. 2010;3:1892-908.

18. Elvira AC, Joseph $Q$, Rossend O. Assessment of diclofenac permeations with different formulations anti-inflammatory study of selected formula. Eur $\mathrm{J}$ Pharm Sci. 2003;19(4):203-10.

19. Dua K, Pabrija K. Acelofenac Topical dosage forms; In vitro and in vivo characterization. Acta Pharm. 2010;60(4):467.

20. Jain H, Patel A, Gadiya S. In vitro release of diclofenac sodium from different topical vehicles, International. Journal Reseaech Pharma Sci. 2011;2(1):26.

Preetam Nikam: Obtained his post-graduate in 2013 from Department of Pharmaceutics, Savitribai 

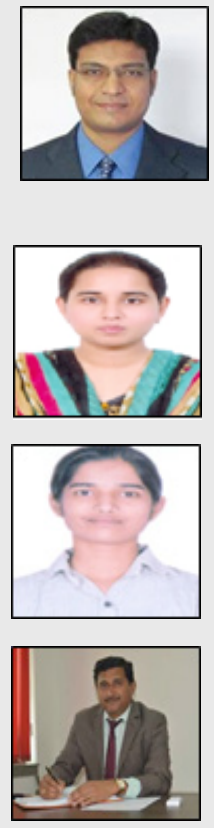

Dr. Ghosh: Has accomplished his Doctorate in Chemistry from the University of Mississippi, USA after completion of M. Sc. from Indian Institute of Technology, Kanpur. He has 5 years of postdoctoral research experience from the renowned universities of the USA along with teaching experiences. Dr. Ghosh has total 16 international publications and presentations in high impact international journals \& conferences. Dr. Ghosh has research experience in the area of electrochemistry, polymer sciences, and advanced materials for renewable energy applications, spectroscopy and analytical chemistry.

Chaitali Deore: She is a student of Master Degree in Quality Assurance Department of Savitribai Phule Pune University, Pune, Maharashtra.

Ashwini Jaybhave: She is a student of Master Degree in Quality Assurance Department of Savitribai Phule Pune University, Pune, Maharashtra.

Dr. Anil Jadhav: Is currently working as Principal at Sandip Institute of Pharmaceutical Sciences, Nashik, Maharashtra. He is Gold medalist of RGUHS during M.Pharmacy. Dr.Jadhav has 48 National and International publications in high impact factor journals, also has 2 books in his credit. Dr.Jadhav is reviewers of many National and International journals. He has research experience in the area of Phytochemical investigation and pharmacological activity.

Cite this article: Talele S, Nikam P, Ghosh BD, Deore C, Jaybhave A, Jadhav AG. A Research Article on Nanogel as Topical Promising Drug Delivery for Diclofenac Nanogel. Indian J of Pharmaceutical Education and Research. 2017;51(4S):S580-S7. 